\title{
LA ACCIÓN TUTORIAL CON FAMILIAS DE ALUMNOS CON NECESIDADES
}

\section{educativas especiales}

DOI

http://dx.doi.org/pym.i360.y2014.004

\section{Gonzalo Martínez VázQuez}

Orientador educativo del colegio Claret de Segovia gmarva@wanadoo.es

odo alumno, por definición, tiene unas necesidades educativas que le hacen único, que le hacen especial y que hacen, o deberían hacer únicas, nuestras intervenciones, nuestra labor con él. Pero en este artículo nos referimos a aquellas familias cuyos hijos padecen algún tipo de deficiencia, sea cual sea la causa y la modalidad. Hablamos de los alumnos con síndromes, trastornos, deficiencias psíquicas, físicas o sensoriales.

Valen, para ellos, todas y cada una de las orientaciones vertidas en los artículos anteriores, si bien hay que tener en cuenta algunos elementos específicos, derivados de sus necesidades especiales, que un profesor-tutor tiene que tener en cuenta a la hora de relacionarse con los padres y de implementar la acción tutorial.

Tras veinte años de experiencia en el Departamento de Orientación de un centro que comenzó siendo de escolarización preferente de deficientes auditivos y que hoy en día escolariza a unos sesenta alumnos con necesidades educativas especiales de cualquier tipología, creo que puedo sintetizar en cuatro fases las tareas que el centro tiene que realizar con la familia a través de la acción tutorial a lo largo de su escolaridad.

\section{Premisas}

I. El alumno no es de un sólo tutor: el camino será largo y serán muchos los tutores que influyan en el proceso de ese alumno. Es importante que el Departamento de Orientación esté muy presente en cualquier acción significativa con ese alumno y con sus padres.

2. Sin embargo, es el tutor de cada curso el que debe liderar las acciones educativas con ese alumno como responsable directo de su educación integral. Asimismo será él el que lidere al resto de profesores en la intervención con el alumno.

3. Hay dos claves de intervención: la primera, la normalización, la segunda, la respuesta a las necesidades específicas que se puedan derivar de la situación de cada alumno.
- En resumen, la tarea fundamental

del tutor en este primer momento es de comprensión y de realismo. Luchar contra la pena, animar a los padres a ver las partes más sanas de su hijo, ayudarles a que acepten el problema como un reto, no como una losa.

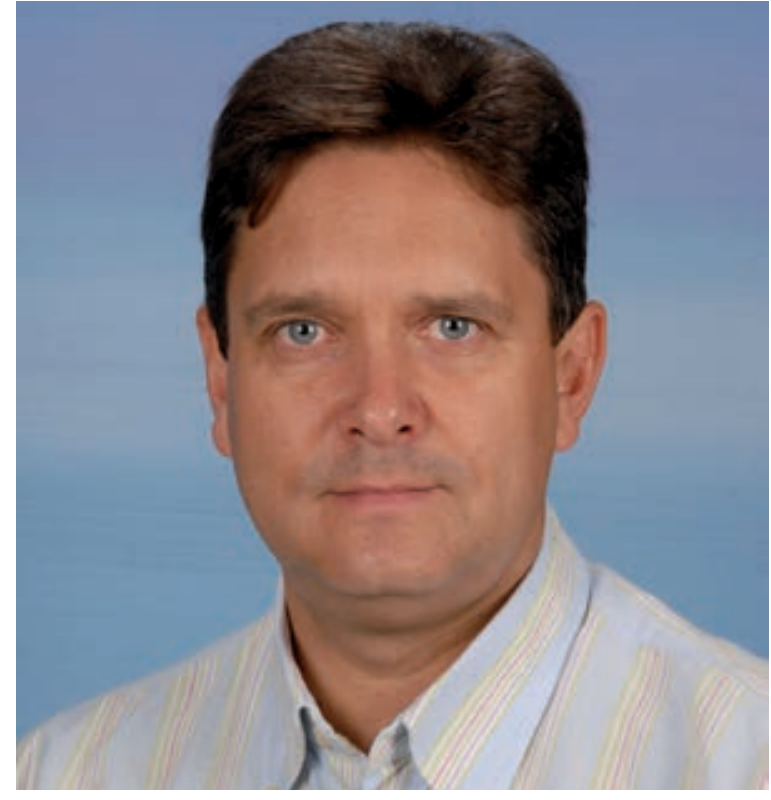

Gonzalo Martínez Vázquez. 


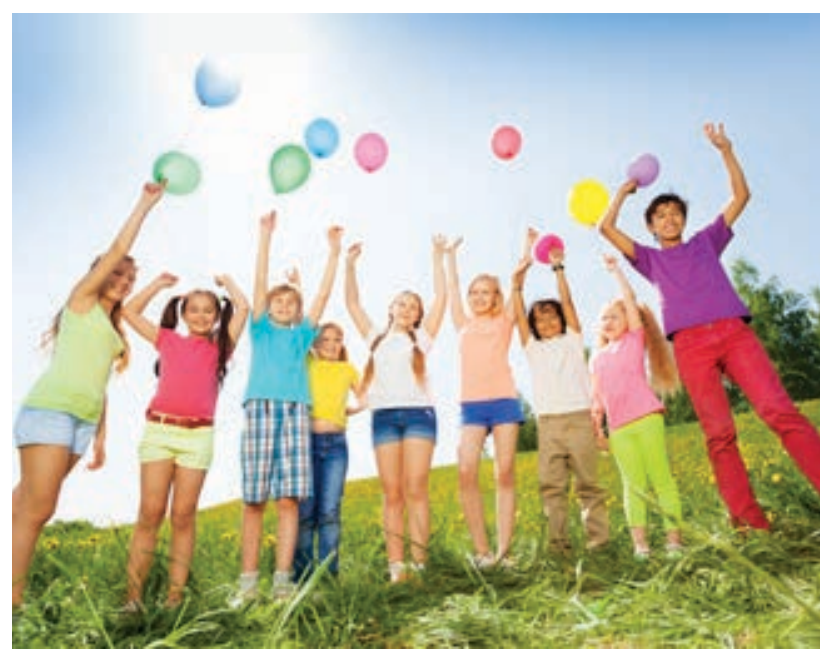

FASE I: ACEPTACIÓN

La fase I suele coincidir con el inicio de la escolaridad o con la aparición (o diagnóstico) de las necesidades especiales. El tutor se enfrenta a la tarea de poner de manifiesto el problema o encarar adecuadamente la manera de encararlo.

Dos peligros y una tarea:

- El primer peligro es la negación: en los primeros momentos, los padres pueden negar la realidad, evitan presentar informes médicos, verbalizan que no pasa nada, que en casa no notan nada raro, se niegan a tratamientos, a apoyos especializados. El tutor, junto con el Departamento de Orientación, debe calmar, comprender, pero ayudar a la familia a aceptar el problema.

- El segundo peligro de esta fase es la hiperprotección: supone adoptar conductas inadecuadas para la edad o para el momento evolutivo del niño. Impiden cualquier situación que suponga al niño un mínimo riesgo, ya sea en la interacción con los demás o en actividades de la vida cotidiana. El trastorno, o el déficit invaden todo el ámbito familiar y la familia gira por completo en torno a la deficiencia. El tutor tiene que dimensionar el problema, hacer ver a los padres que el niño tiene otras muchas esferas sanas que necesitan crecer y desarrollarse, debe impedir que la "enfermedad" contagie todo el sistema, incluido el educativo.

En resumen, la tarea fundamental del tutor en este primer momento es de comprensión y de realismo. Luchar contra la pena, animar a los padres a ver las partes más sanas de su hijo, ayudarles a que acepten el problema como un reto, no como una losa.

\section{FASE 2: LA SOCIALIZACIÓN}

Suele coincidir con los cursos de primaria. Más allá de la mayor o menor adquisición de contenidos y aprendizajes, el reto de esta etapa es el aprendizaje de las habilidades sociales. Éstas sólo se aprenden practicándolas y muchas veces los niños con problemas serios no disponen de momentos para hacerlo.
Dos peligros y una tarea:

- El primer peligro es la comparación. Hay veces que los padres comienzan a comparar a sus hijos desde el déficit. Inevitablemente, el niño con necesidades educativas especiales tiene que hacer un esfuerzo añadido a la hora de relacionarse. Hay padres que no soportan que su hijo se vea enfrentado al estrés que supone lanzarse al mundo. Ven a los demás niños y no creen que su hijo sea capaz de valerse, o tienen miedo a que quede señalada su dificultad. Tienden a restringirle las interacciones, tienden a que se relacione con personas que sí comprendan su especificidad, y le hacen o mayor o menor de lo que es, porque sólo se relaciona con adultos o con niños mucho menores que él.

- El segundo peligro es la dificultad para percibir los cambios en el niño. Cualquier niño crece, evoluciona, los niños con algún trastorno, déficit o situación especial también, y lo que hacíamos con ellos hace algún tiempo, puede no valer ahora. Los padres suelen ralentizar los procesos de crecimiento y cambio. La búsqueda de equilibrio, de estabilidad, vuelve el sistema muy rígido. Les cuesta que cambien de profesor, de compañeros, de pasillo..., el miedo se hace con ellos.

- Tarea del tutor: estar muy atento a provocar aquellos cambios que favorezcan el crecimiento del niño. Si puede hacer algo, que lo haga, si lo puede hacer con los otros, que lo haga, y si lo puede hacer como los otros que lo haga. El miedo paraliza. Es momento de asumir riesgos. El mayor riesgo es la soledad. El profesor deberá provocar situaciones en las que el niño quede expuesto a los demás, en las que tenga que elaborar respuestas nuevas. Que descubra qué habilidades le valen y cuáles no. Calmar la ansiedad de los padres y comprender sus miedos ayuda a que los padres se atrevan a exponer a su hijo a situaciones nuevas.

\section{FASE 3: LOS CAMBIOS}

Esta fase suele darse a lo largo de los cursos de la secundaria y en cada niño puede revestir circunstancias diversas. Tras unos años de cierto equilibrio, correspondientes al segundo o tercer ciclo de primaria, el niño empieza a desarrollarse de otra manera con los padres, con los profesores, con los compañeros y consigo mismo. Es la hora de ser consciente de sí mismo y de su situación.

Dos peligros y una tarea:

- Vuelve a aparecer el fantasma de la negación, de creer que el niño no tiene nada, de que no le afecta lo que le pasa, de que es igual que los demás y de no querer ninguna medida distinta a las que se tomen con los demás. Los padres suelen tener la tentación de renunciar a los apoyos que se le puedan prestar, o de cambiarle de colegio para ver si partiendo de cero el niño pasa desapercibido. 
- En el polo opuesto están los padres que vuelven a vivir cualquier cambio como una amenaza y prefieren que su hijo siga siendo esa personita débil y dependiente que casi nunca formula sus necesidades. Hasta ese momento era muy fácil manejarlo, pero ahora el niño ya no es tan niño y necesita romper con lo que hasta ahora valía para elaborar su propio "Yo". Es un momento de gran confusión, pero un momento necesario para la evolución del niño.

- Tarea del tutor: el profesor-tutor debe poner el foco en el alumno; ver cuál son sus necesidades reales en este momento de su evolución. Tranquilizar a los padres, ya que es un proceso normal, es decir, todos pasan por él, y no viene derivado por sus dificultades. Por otra parte, las dificultades persisten o se agravan, no se pueden achacar al momento evolutivo y el niño sigue necesitando ayuda, apoyos, seguimiento. No es momento de desvincularse, sino de trabajar la responsabilidad de cada uno, incluida la del niño, en su propia vida.

\section{FASE 4: LA LIBERTAD COMO APRENDIZAJE}

Es una de las fases más duras y más bonitas para educadores y padres. Suele corresponder con los últimos años de escolaridad. Hemos trabajado mucho con el niño, con la familia. Es el momento de preparar para la vida.

Dos peligros y una tarea:

- El primer peligro es la utopía (mal entendida). A veces los padres disparan la utopía como salida a una realidad que no les gusta. Piensan en su hijo como capaz de todo porque hemos logrado su socialización y su integración. Planean estudios que

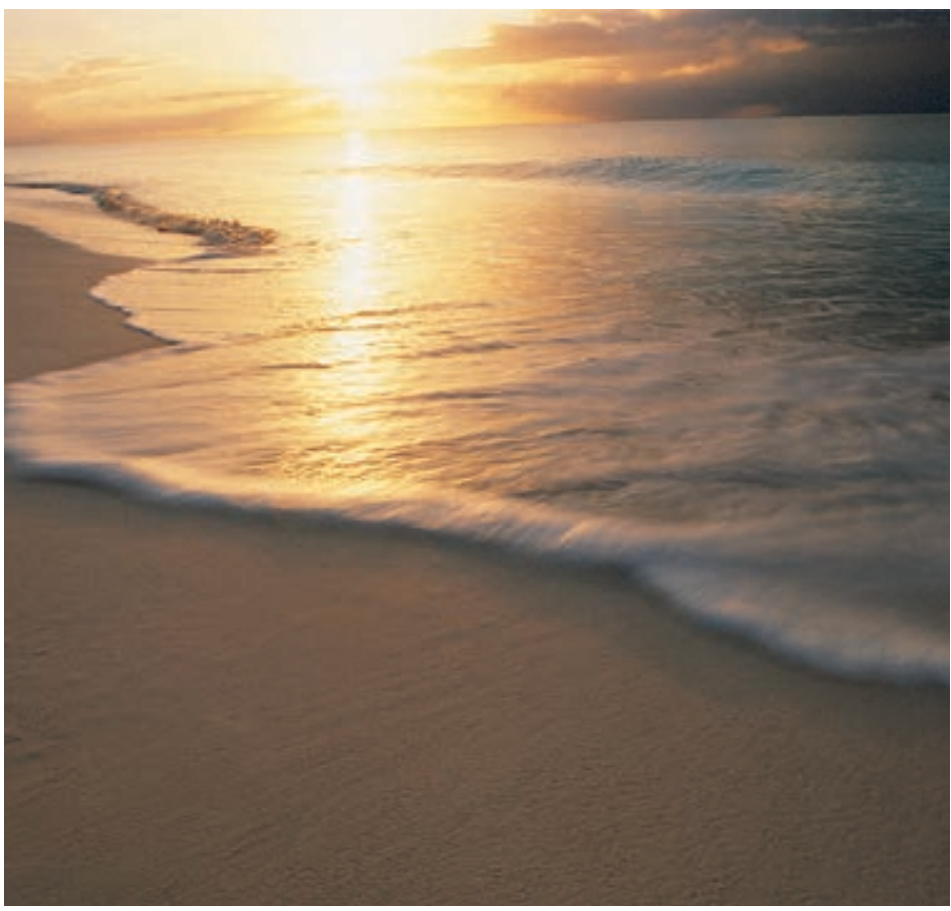

no están al alcance de sus posibilidades, o que quedan muy lejos de las propias expectativas de su hijo. Actúan como si no pasara nada. En la mayor parte de las ocasiones, esta actitud lleva a la frustración y condenan a vivir etapas ya pasadas.

- El segundo peligro es el "miedo a la libertad"; creer que su hijo no va a saber qué hacer fuera del colegio. Intentar que repita curso sin necesidad, que continúe estudiando en el colegio aunque esos estudios no se adecúen a sus necesidades. Los casos más radicales, que vuelva a casa y dé por finalizada su formación, condenándole a la soledad y en muchas ocasiones a la exclusión.

- Tarea del profesor: aquí la tarea es de realismo optimista. Debemos confiar en sus posibilidades, pero no podemos exponerle a una situación de fracaso evidente. Aquí es muy importante anticiparse a los momentos de elección, pensar con el equipo educativo cuál es el mejor camino para el alumno, y preparar el terreno con los padres, trabajarles poco a poco, no dejarlo para el último momento.

\section{ConClusión}

En definitiva, la intervención tutorial con familias de alumnos con necesidades educativas, comparte muchas características con el resto de familias, pero debemos tener en cuenta estos peligros, que son específicos de los alumnos con dificultades serias. El tutor no debe enfrentarse solo a esta tarea. Es imprescindible el concurso de profesores de apoyo, orientadores, trabajadores sociales..., es decir, contar con todo el sistema educativo para así ayudar juntos realmente al alumno a crecer.

\section{Para saber más}

- Arnalz, P. (2003). Educación inclusiva: una escuela para todos. Archidona, Málaga: Aljibe.

- Booth, T. y Ainscow, M. (eds.) (2000). Index for Inclusion. Bristol: Centre for Studies on Inclusive Education.

- Bueno, J. J., Núñez, T., e Iglesias, A. (eds.) (200I). Atención educativa a la diversidad en el nuevo milenio. La Coruña: Universidade de A Coruña.

\section{hemos hablado de:}

\section{Tutoría, orientación educativa, familia y escuela, educación inclusiva, acnee, necesidades educativas especiales.}

Este artículo fue solicitado por PADRES Y MAESTROS en marzo de 2014, revisado y aceptado en octubre de 2014 para su publicación. 